Rodrigo de Sales - Fluminense Federal University

José Augusto Chaves Guimarães — São Paulo State University

\title{
Contributions of Julius Otto Kaiser to the theoretical framework of Knowledge Organization: basis for the analytical-synthetic method ${ }^{1}$
}

\begin{abstract}
In order to highlight the contributions of Kaiser's systematic indexing to the theoretical and methodological landscape of Knowledge Organization, this study presents Kaiser as a pioneer of the analytical-synthetic method and, as a consequence, as a starting point of Ranganathan's faceted theory. In this sense, Kaiser's indexing principles are analyzed in relation to his oeuvres as well as his theoretical convergences with Otlet, Ranganathan, Hulme and Cutter. The methodological approach is based on William James' pragmatism which combines the observation of Kaiser's oeuvres and the identification of his methodological procedures options and propositions that allow us to confirm Kaiser as the pioneer of the analytical-synthetic method in LIS.
\end{abstract}

\section{Introduction}

Knowledge Organization, as a domain whose nature is predominantly operational (Garcia, Oliveira, Luz, 2000; Green, 2002; Garcia Gutiérrez, 2002), has its purposes centered in studying investigating concepts and conceptual structures (Kent, 2000; Green, 2002; Ohly, 2008, Smiraglia, 2010), which are formalized in Knowledge Organization Systems - KOS, such as classification systems, thesauri and ontologies (Albrechtsen, 1990; Kent, 2000; Green, 2002; Zherebchevsky, 2010; Souza; Tudhope e Almeida, 2010). As a consequence, its scope is mostly related to the theoretical and practical dimensions of the subject approach to information (Foskett, 1973).

In the Anglo-American tradition, it is possible to observe at least two different approaches: subject cataloging, mostly related to the development of products like catalogs and subject headings, and indexing, mostly emphasizing the construction of KOS, either in term-based or notation-based forms. Such approaches differ from the French conception of "analyse documentaire" (Coyaud, 1966; Gardin, 1966 a,b, 1967, 1970, 1973, 1984, 1981), whose concerns are centered on the procedures involved rather than the tools (Guimarães \& Tennis, 2012).

The German librarian Julius Otto Kaiser (1868-1927) was originally concerned with systematizing the subject treatment of documents in special libraries and documentation centers and, to do so, he created an indexing system which furnished the basis for the development of the analytical-synthetic method.

Kaiser championed the practice of categorizing as a way to better understand the information that was found on documents. For that, he proposed the construction of subject indexes based on two main categories: concrete and process. Although Ranganathan did not mention the previous studies of Kaiser about subject categories, it is possible to observe that two decades before Ranganathan, Kaiser could propose a

${ }^{1}$ This paper results from a PhD dissertation concluded at the Graduate School of Information Science of São Paulo State University in November 2012. 
structure to analyze and synthesize subjects based on semantic categories. Such a structure was, two decades after, adopted by Ranganathan to consolidate the analyticalsynthetic method during the development of the faceted theory.

Authors such as Cesarino \& Pinto (1978), Rodríguez (1984), Straioto \& Guimarães, (2004), and Dousa (2010a,b) state that Kaiser's categories act as starting point to a faceted theory.

As a consequence, this paper aims to discuss the contribution of Julius Kaiser to the Anglo-American theoretical framework of the subject approach to information (subject cataloging, subject classification and indexing), and, more specifically, his pioneering role in developing the analytical-synthetic method that supports the facet theory, by highlighting theoretical elements to support such argument.

Considering the need to enrich the theoretical framework of subject approach to information, it is especially important to identify and to explain the pioneering theoretical achievements of Kaiser, as a way to contribute to the historiography of Knowledge Organization.

For that reason, we consider that it is especially important to demonstrate evidence the possible dialogues between Kaiser and contemporary KO theoreticians, to identify possible Kaiser's theoretical dimensions on subject indexing, and to specifically point out the evidence that Kaiser has been the pioneer of the conception of the analyticalsynthetic method.

\section{Methodological approach}

It is possible to observe that Kaiser's professional activities in North-American and British special information centers during the end of the 19th and beginning of the 20th century occurred in an environment characterized by the North American philosophical school of pragmatism, led by Charles Sanders Peirce, William James and Olivier Wendell Holmes Jr., which had a considerable influence in the development of KO tools and products. James's pragmatism is focused on the methodological steps and the theoretical possibilities of reaching one's goals. As a consequence, it has been possible to investigate how the procedural systemization of Kaiser's indexing can be considered as a pioneer to the analytical-synthetic method. For that, the conceptions of subject analysis and synthesis in Kaiser's and Ranganathan's methods are studied in order to better understand how they worked in both systems.

The pragmatic observation was empirically supported by the analysis of Kaiser's oeuvres (Kaiser, 1908, 1911) and the analytical and synthetic dimensions extracted from them, making it possible to identify dialogues between Kaiser and other significant KO theorists such as Ranganathan (1967, 1976), Otlet (1903, 1907, 1934) and Cutter (1904).

At the time that Kaiser published his oeuvre, the organization of office services had a considerable development, and the card system was an important practice that emerged in that context. In this sense, Kaiser brings important contributions to the organization of technical and commercial documents. His oeuvre is basically composed by two books: The Card System at the Office, published in London by Vacher \& Sons, in 1908, 
and Systematic Indexing, published by Isaac Pitman \& Sons, in London, in 1911. In those books, Kaiser primarily describes a card system and then explains an indexing system and a method to categorize subjects.

The Card System at the Office presents preliminary information about index construction for offices and specifically refers to the utilization of the system of "simple cards" for organizing documents in a business environment. It presents procedures for recording, storing and retrieving documents.

Systematic Indexing is more specifically related to indexing. Kaiser reviews the literature and discusses matters of classification and management of the guide cards. This text reflects a deeper concern on information analysis and shows that Kaiser first attempted to explain systematic procedures for representing informational items of documents and, in a second moment, he conceived a systematic way to represent subjects. In this sense, Dousa (2010) explains that Kaiser moved from the organization of documents to the organization of ideas embedded in documents.

It is interesting to observe that Kaiser planned a third book called The Card System at the Factory, which was never completed, related to the use of "simple cards" where he intended to explain about the tabulated cards and tabulating methods for representing the subject of documents.

On the other side, Kaiser's oueuvres also have a dialogical relationship with other library theoreticians besides Ranganahtan, such as Otlet, Hulme and Cutter.

\section{Kaiser's theoretical dialogues}

\section{Kaiser and Otlet}

Dousa (2010b) points out the convergence of the information analysis methodologies of Kaiser and Otlet, since once both of them are based on what could be called information units (concepts, facts and evidences which are present in documents). Such elements receive a further rearrangement in order to facilitate the retrieval of information.

Although Kaiser and Otlet had different approaches to organizing information alphabetical order vs. classificatory order - and to the scope of their structures localism in Kaiser vs. universalism in Otlet (Dousa, 2010 b), they also had important convergence points such as: a) the analysis based on parts of the documents'contents, b) the extraction of informative contents from the original structure of the document, in such a way that they could be further combined, c) the analytical record of the extracted concepts from encyclopedic repertoires - Otlet - or from systematic indexes - Kaiser (Sales, 2012), d) the technological support (standardized card systems).

\section{Kaiser and Ranganathan}

It is possible to identify a convergence between Kayser's concept of information analysis and Ranganthan's concept of subject analysis, since both are based on the idea of establishing a structure of knowledge organization based which comes from the identification of subject components. On the other hand, Kaiser's - as well as Otlet's conceptions had a more pragmatic approach because they were concerned on practical 
indexing questions while Ranganathan assumed a more philosophical approach in order to show a rationalist approach in terms of the logical comprehension of knowledge and subjects as well as a pragmatist approach in terms of the final result of his method (Sales, 2012).

The isolate facets proposed by Ranganathan as manifestations of the main categories Energy, Space and Time) also converge with Kaiser's idea of subject components as manifestations of the main categories (Concretes, Process and Countries). In this sense, it is possible to observe that Kaiser and Ranganathan's conceptions have important aspects in common such as: a) the subject analysis through concepts which represent manifestations of facets and categories, b) the definition of a set of main categories (three in Kaiser and five in Ranganathan), c) the establishment of a citation order for those concepts, d) the prevision of a subject statement as a result of the subject synthesis, e) the analytical-synthetic approach as a sequence of procedures related to the decomposition of the document's content into concepts and the consequent rearrangement of the mentioned concepts in a new discursive structure, based on rules and principles.

\section{Kaiser and Hulme}

Hulme's conception of literary warrant can be considered an important method for the development of Knowledge Organization tools, whose main functions consist of justifying and validating the terminology adopted to represent the content of the document as well as the conceptual relations in it (Barité, 2011). Hulme and Kaiser share the idea about the need of adopting a specialized literature as a starting point to ensure a terminological trust in information representation.

\section{Kaiser and Cutter}

The three main principles of Cutter, related to the specificity, use and the syntactic structures among the subjects (Cesarino e Pinto, 1978), were also Kaiser's concerns when he established rules of the elaboration of subject statements. In this sense, the selection of the important and specific information as well as the evaluation of the accuracy of the subject statement to the user are important dialogues with Cutter's conceptions.

Kaiser also promoted the development of Cutters's principles when he pointed out the need to; a) establish subject references (syndetic structures) from specific to general subjects (Foskett, 1973, 1986), b) create coordinate (superordinate and subordinate) networks among the concretes, including synonyms (Mills, 1960), c) ask the user for his feedback on how accurate for his needs the statements are, what is considerably different from Cutter's dedutive conception of what terms could be more suitable to the user's needs (Sales, 2012).

Figure 1 presents a synthesis of Kaiser's theoretical dialogues as mentioned above.

Figure 1. Kaiser's dialogues in knowledge Organization 


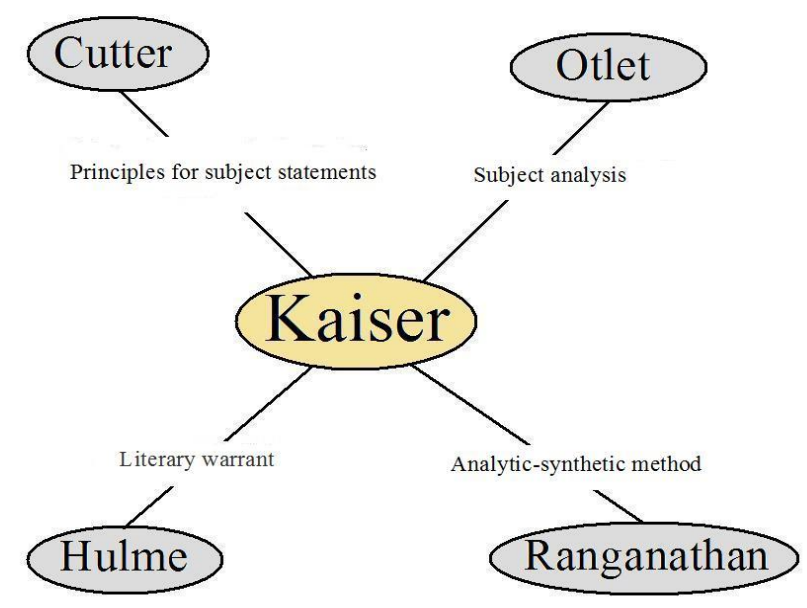

As it can be observed, Kaiser plays an important role in the epistemological landscape of knowledge organization for many reasons. First, he promoted advances in subject cataloging by means of proposing more detailed normative instances for the construction of subject statements. Second, he contributed to bibliographic classification and to indexing by means of the construction of an analythical-synthetic method which acted as a starting point (or even a basis) for the conception of Ranganathan's faceted classification. Furthermore, he not only recognizes the importance of Hulme's literary warrant but also conceives it as a need to ensure a terminological trust in information representation.

\section{Kaiser as pioneer to the analytical-synthetic method: a pragmatic approach}

The analysis of Kaiser's systematic indexing (Kaiser, 1908, 1911) allows us to identify an analytical dimension based on the Aristotelian notion of categorization as a basis for the identification of informative contents (indexing units) by means of the semantic categories Concrete, Country and Process and a synthetic dimension where the subject representation occurs by means of the construction of statements (standardized verbal expressions referring to static and dynamic aspects) and amplifications (sub-categories).

The analytical dimension was based on the conception of categories as general principles to reach the indexing units in the document's content while the synthetic dimension was focused on the modus operandi for the construction of indexes by means of the development of statements. In this sense, the efficacy of the construction of indexes depends on a set of decisions in terms of possible combinations of information derived from the categories as well as in terms of a suitable citation order based on the importance of the categories: concrete - process; country - process; or concrete-country-process.

Kaiser gave more importance to the concreteness of the subjects in such a way that the Concrete (when it happens) stays in a primary position when compared to the other categories (Country and Process). It is also observed by the facts that only the 
categories Concrete and Country can appear as a subject entry. This conception of decreasing concreteness was further adopted by Ranganathan at the PMEST citation order, although Kaiser conceived the Concrete as the more static subject element as possible, while for Ranganathan the more concrete element could result from a cause/effect relationship, in such a way that the cause (why) can be more concrete than the effect (what) (Aranalde, 2009). As a result, the apparent divergence in terms of the concept of concreteness between Kaiser (based on the relationship between static and dynamic stances) and Rangantahtan (based on the relationship between static and dynamic stances) results in a convergence based on the fact that both of them are concerned on priviliging the most concrete subject stances in their citation orders.

The pragmatic comparative analysis of Kaiser's and Ranganathan's systems was based on four points which are the main inference of this study: 1) the elements of the analysis, 2) the procedures of the analysis, 3) the elements of the synthesis and 4) the products of the synthesis, as it can be observe in Table 1.

Table 1. Pragmatisms in Kaiser and Ranganthan

\begin{tabular}{|c|c|c|c|c|}
\hline & $\begin{array}{l}\text { Components of } \\
\text { analysis }\end{array}$ & $\begin{array}{l}\text { Procedures of } \\
\text { analysis }\end{array}$ & $\begin{array}{l}\text { Procedures of } \\
\text { synthesis }\end{array}$ & $\begin{array}{l}\text { Products of } \\
\text { synthesis }\end{array}$ \\
\hline Kaiser & $\begin{array}{l}\text { Words extracted } \\
\text { from the } \\
\text { indexable } \\
\text { literature } \\
\\
\text { Ideational and } \\
\text { Verbal } \\
\text { dimensions }\end{array}$ & $\begin{array}{l}\text { Subject decomposition } \\
\text { into its constituent } \\
\text { parts (categories) } \\
\text { Ideational and Verbal } \\
\text { dimensions }\end{array}$ & $\begin{array}{l}\text { Subject recomposition } \\
\text { by means of the } \\
\text { construction of } \\
\text { concreteness-oriented } \\
\text { verbal statements }\end{array}$ & $\begin{array}{l}\text { Statement } \\
\text { and } \\
\text { amplification } \\
\text { Verbal } \\
\text { dimension }\end{array}$ \\
\hline Ranganathan & $\begin{array}{l}\text { Concepts derived } \\
\text { form subject areas } \\
\text { Ideational and } \\
\text { Verbal } \\
\text { dimensions }\end{array}$ & $\begin{array}{l}\text { Subject decomposition } \\
\text { into its constituent } \\
\text { parts (facets and } \\
\text { categories) } \\
\text { Ideational and Verbal } \\
\text { dimensions }\end{array}$ & $\begin{array}{l}\text { Subject recomposition } \\
\text { by means of the } \\
\text { construction of } \\
\text { concreteness-oriented } \\
\text { notational statements }\end{array}$ & $\begin{array}{l}\text { Classificatory } \\
\text { notation } \\
\text { Notational } \\
\text { dimension }\end{array}$ \\
\hline
\end{tabular}

If we conceive William James' pragmatism as a tool (the action as a purpose) and not as an aim it is possible to visualize both Kaiser's and Ranganathan's systems whose input elements are the components of analysis, and which are processed (i.e., the procedures of analysis and synthesis) in order to get the products of synthesis as an output.

It is important to observe that both Kaiser and Ranganathan based their analytical dimension on the decomposition of the subject into its constituents, what reveals a transition between the ideational dimension (the definition of subject categories) and 
verbal dimension (the terminological shape given to the subject contents). As a consequence, their synthetic dimension provide a subject recomposition into subject statements (verbal ones for Kaiser, and notational ones for Ranganathan) whose citation order is based on the concreteness degree of the categories.

The pragmatic approach mentioned above allows us to confirm the idea that Kaiser was the pioneer of the analytical-synthetic method when he combined subject analysis with subject representation according to highly structured rules (Svenonius, 2000) resulting in analytical-synthetic indexes which offered a background for the further development of analytical-synthetic classification by Ranganathan.

\section{Conclusion}

In terms of dialogical points between Kaiser and other important KO theoreticians, it was possible to observe that Kaiser and Otlet shared the conception of information analysis based on "constituent" or "informative elements", in such a way that Otlet privileged the so-called "information units" (concepts and facts) while Kaiser referred to them as "indexable units." Kaiser keeps a kind of relation of continuity with Cutter in terms of the definition of rules for elaborating subject statements, since both were concerned with building tools and products of terminological subject representation. Both Kaiser and Cutter promoted guidelines for the elaboration of subject headings and of subject statements, what reveals a common concern with the establishment of rules for the professional activities of catalogers and indexers. A comparison of the pragmatism in Kaiser's and Ranganathan's methods made it possible to observe that both of them were composed by inputs (the elements of analysis), means (development of analysis and synthesis procedures) and outputs (the products of the synthesis). Although the inputs and outputs are conceptually different in both of the systems, they present a clear intersection in the means to develop the analysis and, based on that, in the way to arrive to a subject synthesis.

Therefore, the observation of the elements of analysis, the development of the analysis and synthesis procedures and the products of the synthesis demonstrate that Kaiser shared the conception of subject analysis with Otlet, as well as the standardization of subject statements with Cutter and those elements allow him to act as a pioneer in the conception of the analytical-synthetic method in knowledge organization, which was further developed by Ranganathan.

This allows us to affirm that Kaiser was not only a Ranganathan's predecessor but, mainly, the first author, in modern times, to approach a systematic way to analyze and synthesize subjects by means of a set of categories. And considering that the analyticsynthetic method figures as one of the main foundations of knowledge organization theory, it is especially important to highlight the nuclear role of Kaiser to the theoretical construction of Knowledge Organization.

\section{References}

Albrechtsen, H. 1990. Software concepts: Knowledge Organization and the human interface. In: Tools for knowledge organization and the human interface: Proceedings of the 1st International ISKO Conference Frankfurt/Main: Indeks, p, 48. 
Andersen, J. 2008. Knowledge Organization as a Cultural Form: From Knowledge Organization to Knowledge Design In: In: Culture and identity in knowledge organization: Proceedings of the Tenth International ISKO Conference Würzburg: Ergon, p. 269.

Barité, M. 2011. La garantía literaria como herramienta de revisión de sistemas de organización del conocimiento: modelo y aplicación. 2011. 360 f. Tese (Doutorado em Información Científica) - Facultad de Comunicación y Documentación. Universidad de Granada.

Cesarino, M. A. da N.; Pinto, M. C. M. F. 1978. Cabeçalho de assunto como linguagem de indexação. Revista da Escola de Biblioteconomia, UFMG, Belo Horizonte, ano 7, set. 1978, n. 2, p. 268-88.

Coyaud, M. 1966. Introduction à l'étude des langages documentaires. Paris: Klinsieck.

Cutter, C. A. 1904. Rules for a dictionary catalog. 4 ed. Washington: Government Printing Office, (U.S. Bureau of Education. Special Report on Public Libreries; 2).

Dousa, T. M. 2010a. Facts and frameworks in Paul Otlet's and Julius Otto Kaiser's theories of knowledge organization. Bulletin of the American Society for Information Science and Technology, v. 36, n. 2, p. 19-25, dez./jan. 2010.

Dousa, T. M. 2010b. Julius Otto Kaiser's systematic indexing: a study of its theoretical content in its historical context. 2010 b. 71 f. Report (PhD in Philosophy in Library and Information Science) - Graduate College.University of Illinois. Urbana-Champaign.

Foskett, A. C. 1973. A abordagem temática da informação. Tradução de Antônio Agenor Briquet de Lemos. São Paulo: Polígono; Brasília: Ed.UnB.

Foskett, A. C. 1986. The subject approach to information. 5. ed. London: Clive Bingley.

Gárcia Gutiérrez, A. L. 2002. Knowledge Organization From a Culture of the Border: Towards a Trascultural Ethics of MediationIn: Challenges in knowledge representation and organization for the 21st century: Integration of knowledge across boundaries: Proceedings of the Seventh International ISKO Conference Würzburg: Ergon, p.518

Garcia, S. M. M,; Oliveira and Luz, G. M. S. 2000. Knowledge Organization for Query Elaboration and Support for Technical Response by the Internet In: Dynamism and stability in knowledge organization: Proceedings of the Sixth International ISKO Conference Würzburg: Ergon. p.189

Gardin, J.-C. 1966a. Analyse et sélection documentaires sans les sciences humaines. In: Leroy, A. Enseignement préparatoire aux techniques de la documenation automatique. Bruxelles, Euratom, p.137-146.

Gardin, J.-C. 1966b. Eléments d'un modèle pour la description des lexiques documentaires.:

Bulletin des Bibliothèques de France, v. 11, n. 5. p. 171-182.

Gardin J-C. 1967. Recherches sur l'indexation automatique des documents scientifiques. Revue d'informatique et de recherche opérationnelle, 1ere année, n.6, p.27-46.

Gardin, J.-C. 1970. Procédures d'analyse sémantique dans les sciences humaines. In : Pouillon, J. , Maranda, P. (Org.) Échanges et communications: mélanges offerts à Claude LéviStrauss à l'ocasion de son 60ème anniversaire. [The Hague] : Mouton,. p. 628-657.

Gardin, J.-C. 1973. Document analysis and linguistic theory. Journal of Documentation, v. 29, n. 2, p. $137-168$.

Gardin J-C. 1974. Analyse documentaire et théorie linguistique. In: Les analyses de discours. Neuchatel : Delachaux et Niestlé, p. 120-168.

Gardin, J.-C. et al. 1981. La logique du plausible: essais d'épistemologie pratique. Paris: Maison des Sciences de 1'Homme.

Green, R. 2002. Conceptual Universals in Knowledge Organization and Representation In: Challenges in knowledge representation and organization for the 21st century: Integration of knowledge across boundaries: Proceedings of the Seventh International ISKO Conference. Würzburg: Ergon, p.15.

Guimarães, J. A. C. ; Tennis, J. T. 2012. Constant pioneers: the citations frontiers of indexing theory in the ISKO international proceedings. In: A. Neelameghan; K.S. Raghavan. (Org.). 
de Sales, R., \& Guimarães, J. (2013). Contributions of Julius Otto Kaiser to the theoretical framework of Knowledge Organization: basis for the analytical-synthetic method. NASKO, 4(1). Retrieved from http://journals.lib.washington.edu/index.php/nasko/article/view/14656

Categories, contexts and relations in knowledge organization: Proceedings of the Twelveth International ISKO Conference..Würzburg: Ergon Verlag, 2012, v. , p. 39-43.

James, W. P. 2006. Pragmatismo. Trad. Jorge Caetano da Silva. São Paulo: Martin Claret.

Jurisica, I. 2000. Knowledge Organization by Systematic Knowledge Management and Discovery In: Dynamism and stability in knowledge organization: Proceedings of the Sixth International ISKO Conference. Würzburg: Ergon. p.366

Kaiser, J. O. 1911. Systematic indexing. London: Isaac Pitman \& Sons.

Kaiser, J. O. 1908. The card system at the office. London: Vacher \& Sons, (The Card System Series, 1).

Kent, R. E. 2000. The Information Flow Foundation for Conceptual Knowledge Organization In: Dynamism and stability in knowledge organization: Proceedings of the Sixth International ISKO Conference. Würzburg: Ergon. p. 111.

Mills, J. 1960. A morden outline of library classification. London, Chapman and Hall.

Ohly , H. P. 2008. Knowledge Organization Pro Retrospective In: Culture and identity in knowledge organization: Proceedings of the Tenth International ISKO Conference. Würzburg: Ergon, p. 210.

Otlet, P. 1903. The science of bibliography and documentation. In W. B. Rayward (Ed. \& trans.), International organization and dissemination of knowledge: Selected essays of Paul Otlet (pp. 71-86). Amsterdam: Elsevier, 1990.

Otlet, P. 1907. The systematic organization of documentation and the development of the International Institute of Bibliography. In W. B. Rayward (Ed. \& trans.), International organization and dissemination of knowledge: Selected essays of Paul Otlet (pp. 105-111). Amsterdam: Elsevier, 1990.

Otlet, P. 1934. Traité de documentation. Le livre sur le livre: Théorie et pratique. Bruxelles: Editiones Mundaneum.

Ranganathan, S. R. 1976. Colon classification. 6. ed., 4. reimpr. Bombay; Calcutta; New Delhi; Madras; Lucknow; Bangalore; London; New York: Asia Publishing House.

Ranganathan, S. R. 1967. Prolegomena to library classification. Bombay: Asia Publishing House.

Rodriguez, R. D. 1984. Kaiser's systematic indexing. Library Resources \& Technical Services, apr./jun., p. 163-173.

Sales, R. de. 2012. A presença de Kaiser no quadro teórico do tratamento temático da informação / The presence of Kaiser in the theoretical landscape of the subject approach to information (2012). $190 \mathrm{f}$. Dissertation (PhD in Information Science) - Graduate School of Information Science. São Paulo State University - UNESP - Marília.

Smiraglia, R. P. 2010. Perception, Knowledge Organization and noetic affective social tagging. In: In :Paradigms and conceptual systems in knowledge organization: Würzburg: Ergon, p.64.

Souza, R. R.; Tudhope, D.; Almeida, M. B. 2010. The KOS spectra: a tentative faceted typology of Knowledge Organization systems. In: Paradigms and conceptual systems in knowledge organization: Proceedings of the Eleventh International ISKO Conference. Würzburg: Ergon, p.122.

Straioto, A. C.; Guimaraes, J. A. C. 2004. A abordagem facetada no contexto da organização do conhecimento: elementos históricos. Páginas a\&b (arquivos \& bibliotecas), Lisboa, n.14, p.109-136.

Svenonius, E. 2000. The intellectual foundation of information organization. Cambridge: MIT

Zherebchevsky. 2010. Formalism in Knowledge Organization. In: In: Paradigms and conceptual systems in knowledge organization: Proceedings of the Eleventh International ISKO Conference. Würzburg: Ergon, p. 98. 